\title{
PERFORMANCE-BASED SEISMIC DESIGN OF A RETAINING WALL
}

\author{
Carlos Jurado Cabañes (Ph. D.) \\ Polytechnic University of Madrid \\ C/ Alfonso XII, 3 y 5, 28014 Madrid, Spain \\ e-mail: cjurado@ciccp.es
}

Keywords: Gravity wall, overturning, sliding, critical acceleration.

\begin{abstract}
The design of containment walls suffering seismic loads traditionally has been realized with methods based on pseudoanalitic procedures such as Mononobe-Okabe's method, which it has led in certain occasions to insecure designs, that they have produced the ruin of many containment walls suffering the action of an earthquake. The recommendations gathered in Mononobe-Okabe's theory have been included in numerous Codes of Seismic Design. It is clear that a revision of these recommendations must be done. At present there is taking place an important review of the design methods of anti-seismic structures such as containment walls placed in an area of numerous earthquakes, by means of the introduction at the beginning of the decade of 1990 the Displacement Response Spectrum (DRS) and the Capacity Demand Diagram (CDD) that suppose an important change in the way of presenting the Elastic Response Spectrum (ERS). On the other hand in case of action of an earthquake, the dynamic characteristics of a soil have been referred traditionally to the speed of the shear waves that can be generated in a site, together with the characteristics of plasticity and damping of the soil. The Principle of the energy conservation explains why a shear upward propagating seismic wave can be amplified when travelling from a medium with high shear wave velocity (rock) to other medium with lower velocity (soil deposit), as it happened in the earthquake of Mexico of 1985. This amplification is a function of the speed gradient or of the contrast of impedances in the border of both types of mediums. A method is proposed in this paper for the design of containment walls in different soils, suffering to the action of an earthquake, based on the Performance-Based Seismic Design.
\end{abstract}




\section{INTRODUCTION}

The calculation of the static and dynamics pressures of a soil against a wall, as well as the displacements of it under the action of an earthquake, can be realized by means of analytical pseudostatic, analytical dynamic methods or by means of numerical methods: finite differences, finite elements, etc.

For the first methods, different authors $\left(\right.$ Coulomb $^{[2]}$, Rankine ${ }^{[12]}$, Newmark ${ }^{[7]}$, RichardsElms ${ }^{[13]}$, Whitman-Liao ${ }^{[16]}$, Prakash-Rafnsson- $\left.\mathrm{Wu}^{[8]}{ }^{[9]}\right)$ have developed approximations to the problem, consisting of analytical pseudostatic solutions, presenting in every case different limitations. Other authors (Wood ${ }^{[17]}, \operatorname{Scott}^{[14]}$, Veletsos and Younan ${ }^{[15]}$ ) have obtained analytical dynamic solutions based on the theory of the elastic waves.

For the numerical methods different commercial programs have been developed: SASSI ${ }^{[5]}$, PLAXIS $^{[1]}$, FLAC/FLAC3D, etc.

The latter programs need normally a high time of preparation of input and an important consumption of computation. On the other hand few of them allow the integration of the dynamic equations in the time domain. Another limitation is the model behavior of the soil implemented in the program.

The analytical pseudostatic methods on the contrary, need a minor time of computer and have been implemented in the past for the calculation of walls submitted to static actions with satisfactory results.

For preliminary studies a program of computer have been developed by means of analytical pseudostatic methods for the calculation of the pressures and displacements of a gravity retaining wall, in static and dynamic conditions under the action of one earthquake. The situations of stability are verified to sliding and overturning, warning in case of failure, to increase the dimensions of the wall.

The analysis of a gravity wall submitted to the action of an earthquake by means of the calculation of the possible permanent displacement follows the line of the method of Performance Based Design.

\section{PROGRAM MUROSIS}

For the analysis of the behavior of a wall submitted to seismic actions, it have been developed the program MUROSIS based on pseudoanalític methods, for the calculation of static and seismic pressures on the back of the wall, as well as the permanent seismic displacement, in case the maximum acceleration of the earthquake overcomes the critical acceleration (Whitman-Liao ${ }^{[16]}, 1983$ ).

The program calculates the total force and the moment at the base of the wall. The force in static conditions is calculated by Rankine's method or by Coulomb's method. The seismic force is calculated by Mononobe-Okabe's method, considering his action with agreement to Richards-Elms ${ }^{[13]}$ of $0.66 \mathrm{H}$ over the foot of the wall, being $\mathrm{H}$ the height of it.

Later it is calculated the maximum friction force that is opposed to the sliding and the stabilizing moment, obtaining finally the safety coefficients for sliding and overturning, in static and also in seismic conditions. In case the safety coefficient of sliding or overturning does not fulfill a prescribed valor the program warns to increase the dimensions of the wall. 


\section{STATIC ACTIVE FORCE ACCORDING TO COULOMB'S THEORY}

The static pressure according to Coulomb's theory on a wall of vertical back line has the expression:

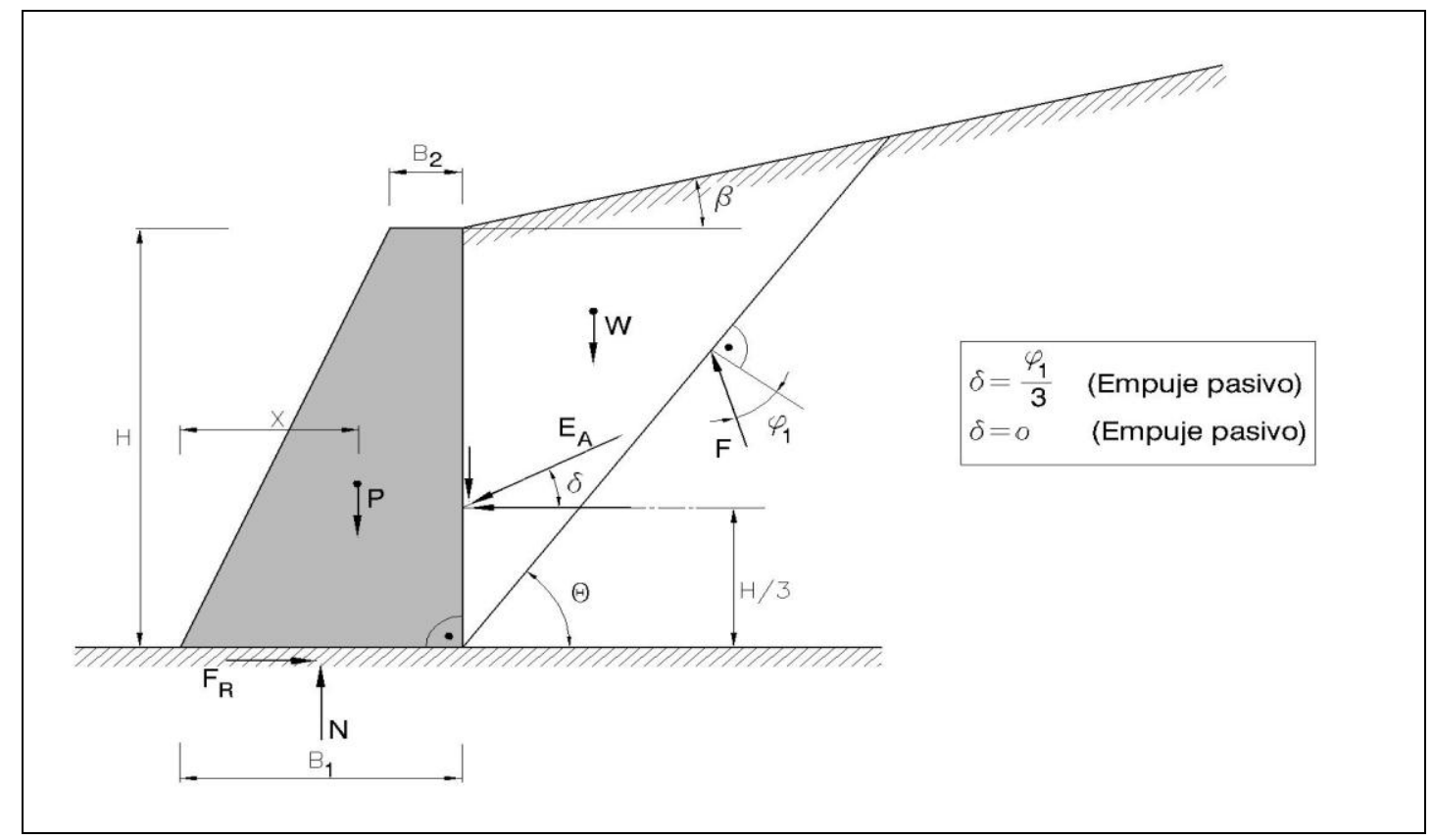

Figure 1. Static pressure against a wall according Coulomb's theory

Active force:

$$
\begin{gathered}
E_{A}=\frac{1}{2} \gamma K_{A} H^{2} \\
K_{A}=\frac{\cos ^{2} \varphi_{1}}{\cos \left[1+\sqrt{\frac{\operatorname{sen}\left(\varphi_{1}+\delta\right) \cdot \operatorname{sen}\left(\varphi_{1}-\beta\right)}{\cos \delta \cdot \cos \beta}}\right]^{2}} \\
K_{A h}=K_{A} \cos \delta \quad K_{A V}=K_{A} \operatorname{sen} \delta \\
E_{A h}=\frac{1}{2} \gamma K_{A h} H^{2} \quad E_{A V}=\frac{1}{2} \gamma K_{A V} H^{2} \\
F_{e}=F{ }_{R}=\mu N=\left(P+E_{A V}\right) \operatorname{tg} \phi_{2} \quad F_{d}=E_{A h} \\
M_{e}=P \cdot x+E_{A V} \cdot B_{1} \quad M_{V}=E_{A h} \cdot \frac{H}{3}
\end{gathered}
$$

The total active force according to Coulomb's theory forms an angle $\delta$ with the normal to the wall (figure 1) 


\section{DYNAMIC ACTIVE FORCE ACCORDING MONONOBE-OKABE'S THEORY}

With the conditions established in the program MUROSIS for a wall with vertical back line $\left(\mathrm{i}=0^{\circ}\right)$, granular landfill (Mononobe-Okabe does not consider cohesion), friction angle of landfill - wall $\delta \neq 0$ and angle of inclination of the surface of the area $\beta \neq 0$, the formulation used by the program calculates the active and passive pressures with the point of application defined by Prakash ${ }^{[13]}$, Richards-Elms ${ }^{[13]}$, Whitman-Liao ${ }^{[16]}$.

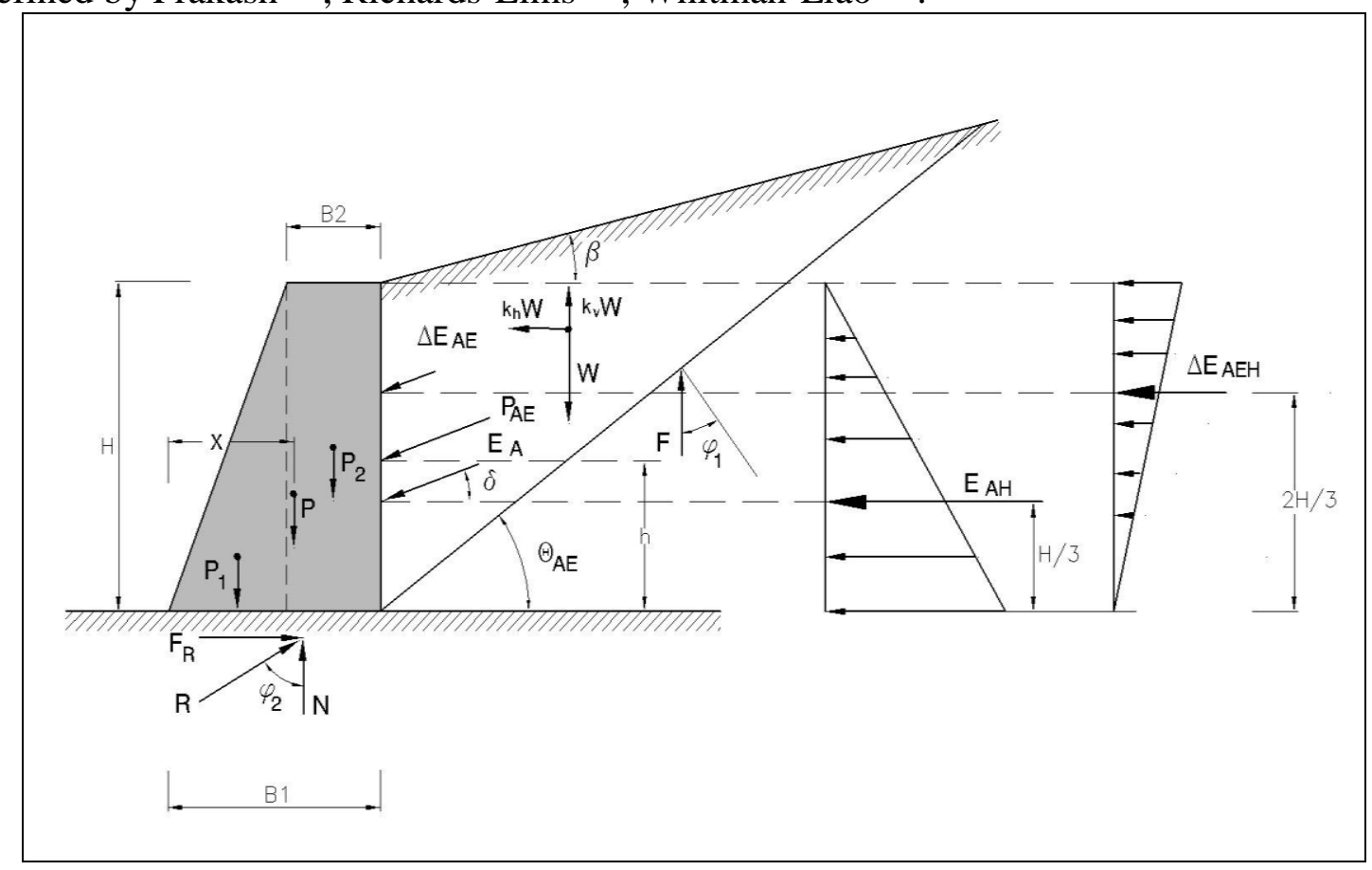

Figure 2. Dynamic pressure against a wall according Coulomb's theory

Active force:

$$
\begin{gathered}
P_{A E}=\frac{1}{2} \gamma H^{2}\left(1-k_{v}\right) \frac{\cos ^{2}(\varphi-\psi)}{\cos \psi \cos ^{2} i \cos (\delta+\psi)\left[1+\sqrt{\frac{\operatorname{sen}(\delta+\varphi) \operatorname{sen}(\varphi-\beta-\psi)}{\cos (\delta+\psi) \cos \beta}}\right]^{2}} \\
\psi=\operatorname{arctg} \frac{k_{h}}{1-k_{v}} \quad \varphi \geq \psi \\
K_{A E}=\left(1-k_{V}\right) \frac{\cos ^{2}(\varphi-\psi)}{\cos \psi \cos ^{2} i \cos (\delta+\psi)\left[1+\sqrt{\frac{\operatorname{sen}(\delta+\varphi) \operatorname{sen}(\varphi-\beta-\psi)}{\cos (\delta+\psi) \cos \beta}}\right]^{2}}
\end{gathered}
$$

Where $\boldsymbol{P}_{\boldsymbol{A} \boldsymbol{E}}=\boldsymbol{E}_{\boldsymbol{A}}+\boldsymbol{\Delta} \boldsymbol{E}_{\boldsymbol{A} \boldsymbol{E}}$, being $\mathrm{E}_{\mathrm{A}}$ the active force according to Coulomb's theory and $\Delta \mathrm{E}_{\mathrm{AE}}$ the active seismic force, with the value:

$$
\Delta E_{A E}=\frac{1}{2} \gamma H^{2}\left(K_{A E}-K_{A}\right)
$$

Where $\boldsymbol{k}_{\boldsymbol{h}} \mathrm{y} \boldsymbol{k}_{\boldsymbol{v}}$ are the horizontal and vertical seismic coefficient accelerations relative to $\mathbf{g}$, that is the horizontal and vertical pseudostatic accelerations are: $\boldsymbol{a}_{\boldsymbol{h}}=\boldsymbol{k}_{\boldsymbol{h}} \boldsymbol{g}$ y $\boldsymbol{a}_{\boldsymbol{v}}=\boldsymbol{k}_{\boldsymbol{v}} \boldsymbol{g}$. 
The coefficient $\boldsymbol{k}_{\boldsymbol{v}}$ can have positive or negative sign, if the vertical acceleration due to the earthquake is ascending or descending.

The total active force $\mathrm{P}_{\mathrm{AE}}$ has his point of application at a height on the base of the wall of:

$$
h=\frac{E_{A} \cdot \frac{H}{3}+\Delta E_{A E} \cdot \frac{2 H}{3}}{P_{A E}}
$$

Once calculated $\boldsymbol{K}_{\boldsymbol{A} E}$, it can be obtained:

$$
\begin{aligned}
& \mathrm{K}_{\mathrm{AEH}}=\mathrm{K}_{\mathrm{AE}} \cos \delta \\
& \mathrm{E}_{\mathrm{AEH}}=1 / 2 \gamma \mathrm{K}_{\mathrm{AEH}} \cdot \mathrm{H}^{2} \\
& \mathrm{~F}_{\mathrm{e}}=\mathrm{F}_{\mathrm{R}}=\mu \mathrm{N}=\left(\mathrm{P}+\mathrm{E}_{\mathrm{AV}} \pm \mathrm{E}_{\mathrm{AEV}}\right) \cdot \operatorname{tg} \varphi_{2} \\
& \mathrm{M}_{\mathrm{e}}=\mathrm{P} \cdot \mathrm{x}+\mathrm{E}_{\mathrm{AV}} \cdot \mathrm{B}_{1} \pm \mathrm{E}_{\mathrm{AEV}} \mathrm{B}_{1}
\end{aligned}
$$$$
\mathrm{K}_{\mathrm{AEV}}=\mathrm{K}_{\mathrm{AE}} \operatorname{sen} \delta
$$$$
\mathrm{E}_{\mathrm{AEV}}=1 / 2 \gamma \mathrm{K}_{\mathrm{AEV}} \cdot \mathrm{H}^{2}
$$$$
\mathrm{F}_{\mathrm{d}}=\mathrm{E}_{\mathrm{AH}}+\Delta \mathrm{E}_{\mathrm{AEH}}
$$$$
\mathrm{M}_{\mathrm{V}}=\mathrm{E}_{\mathrm{AH}} \cdot \frac{H}{3}+\Delta \mathrm{E}_{\mathrm{AEH}} \cdot \frac{2 H}{3}
$$

The safety coefficients with the action of earthquake are:

$$
F S D=\frac{F_{e}}{F_{d}} \geq 1.1 \quad \text { and } \quad F S V=\frac{M_{e}}{M_{v}} \geq 1.5
$$

\section{PERFORMANCE-BASED SEISMIC DESIGN OF A WALL}

In a containment wall with the action of an earthquake, when the horizontal acceleration is lower than a critical or limit value $\mathbf{a}_{\text {crit }}$, the wall does not suffer movement.

But, when the acceleration of the soil equals the critical or limit acceleration, the wall is in situation of imminent sliding. In this instant the total active forces due to the static and seismic pressures equal the stabilizing force due to the friction between the wall and the soil at the base.

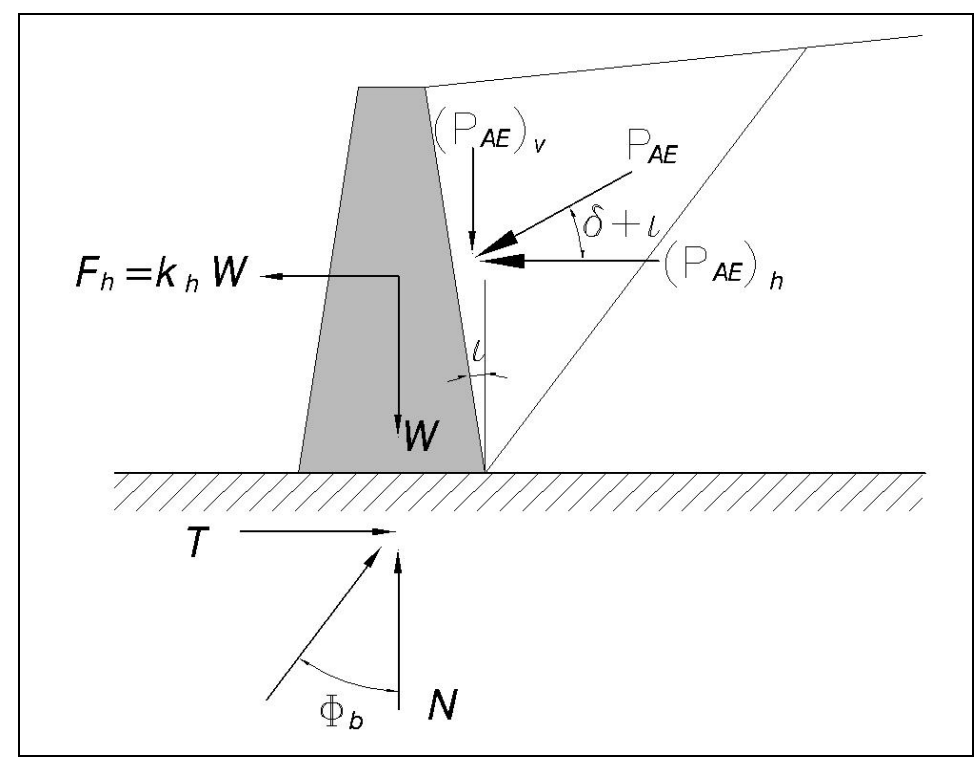

Figure 3 Seismic forces on the wall by MONONOBE-OKABE

Considering only horizontal acceleration and naming PAE the total static and seismic force calculated by Mononobe-Okabe's method and by $(\mathrm{PAE})_{\mathrm{h}}$ and $(\mathrm{PAE})_{\mathrm{v}}$ the horizontal and vertical components of this, the horizontal and vertical balance of forces on the wall (figure 3.) direct to:

$$
\mathrm{T}=\mathrm{F}_{\mathrm{h}}+\left(\mathrm{P}_{\mathrm{AE}}\right)_{\mathrm{h}}
$$


Substituting in these equations:

$$
\mathrm{N}=\mathrm{W}+\left(\mathrm{P}_{\mathrm{AE}}\right)_{\mathrm{v}}
$$

$$
T=N \operatorname{tg} \Phi_{b} ; \quad F_{h}=a_{c r i t} \frac{W}{g} ; \quad P_{A E}{ }_{h}=P_{A E} \cos \delta+\imath ; \quad P_{A E}{ }_{v}=P_{A E} \operatorname{sen} \delta+\imath
$$

Where $t$ is the inclination of the back of the wall with the vertical one and $\delta$ is the friction angle between soil and wall, obtaining the value of the limit or critic acceleration that it puts in situation of imminent sliding the wall:

$$
\begin{aligned}
& N \operatorname{tg} \Phi_{b}=a_{c r i t} \frac{W}{g}+P_{A E} \cos (\delta+\imath) \\
& N=W+P_{A E} \operatorname{sen}(\delta+\imath)
\end{aligned}
$$

Then:

$$
W+P_{A E} \operatorname{sen}(\delta+\imath) \operatorname{tg} \Phi_{b}=a_{c r i t} \frac{W}{g}+P_{A E} \cos (\delta+\imath)
$$

Wherefrom:

$$
a_{c r i t}=\left(\operatorname{tg} \Phi_{b}-\frac{P_{A E} \cos \delta+\imath-P_{A E} \operatorname{sen} \delta+\imath \operatorname{tg} \Phi_{b}}{W}\right) g
$$

Being $\boldsymbol{\Phi}_{\mathbf{B}}$ the friction angle between the base of the wall and the underlying soil. In this equation $\mathbf{P}_{\mathbf{A E}}$ 's value must be obtained with Mononobe-Okabe's method.

The solution of this equation must be solved by iterative form, since before to calculate PAE's value by Mononobe-Okabe's method is needed to know the value of $\mathbf{a}_{\text {crit }}$, and it is necessary to proceed by trial and error.

Richards y Elms ${ }^{[13]}$ (1979) have calculated the permanent displacement of the wall when $\mathrm{a}_{\max }>\mathrm{a}_{\text {crit }}$ obtaining the value:

$$
\mathrm{D}_{\text {perm }}=0,087 \frac{V_{\max }^{2} \cdot a_{\max }^{3}}{a_{\text {crit }}^{4}}
$$

Whitman y Liao ${ }^{[16]}$ (1983) correcting Richards-Elms's simplifications have proposed the following expression for the permanent seismic displacement:

$$
\mathrm{d}_{\text {perm }}=\frac{37 V_{\max }^{2}}{a_{\max }} \cdot e^{-9,4\left(\frac{a_{\text {crit }}}{a_{\max }}\right)}
$$

This value must not overcome the admissible limit for the permanent displacement of the wall. If this value is exceeded, it is necessary to increase the dimensions of the wall.

\section{ORDER FOLLOWED BY THE PROPOSED PROGRAM}

The order followed by the program is.

1. First it calculates the weight $\mathrm{W}$ of the wall

2. A previous value of $\mathbf{a}_{\mathbf{h}}=\mathbf{k}_{\mathbf{h}} \cdot \mathbf{g}$, will be supposed calculating for the value of $\mathbf{a}_{\mathbf{v}}=\mathbf{k}_{\mathbf{v}} \cdot \mathbf{g}$, the total active force by Mononobe-Okabe's method.

3. For the value $\mathrm{P}_{\mathrm{AE}}$ it calculates the critical or limit acceleration:

$$
a_{c r i t}=\left(\operatorname{tg} \Phi_{b}-\frac{P_{A E} \cos \delta+\imath-P_{A E} \operatorname{sen} \delta+\imath \operatorname{tg} \Phi_{b}}{W}\right) g
$$


4. If the value of $\mathbf{a}_{\text {crit }}$ differs of $\mathbf{a}_{\mathbf{h}}=\mathbf{a}_{\max }$ less than the one prearranged value $(0,001)$, it calculates the permanent displacement by Whitman-Liao's method according with the equation:

$$
\mathrm{d}_{\text {perm }}=\frac{37 V_{\max }^{2}}{a_{\max }} \cdot e^{-9,4\left(\frac{a_{c r i t}}{a_{\max }}\right)}
$$

5. If the value of $\mathbf{a}_{\text {crit }}$ differs of $\mathbf{a}_{\mathbf{h}}=\mathbf{a}_{\text {max }}$ more than the one prearranged, new intermediate value $\mathbf{a}_{\max }$ is used, following with the process, until $\mathbf{a}_{\text {crit }}$ and $\mathbf{a}_{\max }$ fulfill this condition.

6. The value of $d_{\text {perm }}$ finally calculated must be less than the prearranged limit value and in contrary the dimensions of the wall must be increased until the mentioned condition is fulfilled.

\section{STUDIED CASES}

It has been realized the seismic calculation of 16 cases of walls by means of the program named MUROSIS, using the next two types of walls:

1. Wall with $4,00 \mathrm{~m}$ of height

2. Wall with $6,00 \mathrm{~m}$ of height

In both cases the static pressures have been calculated by Coulomb's theory. The dynamic pressures have been obtained by Mononobe-Okabe and the permanent seismic possible displacements by Whitman-Liao. All the exits have been verified manually and with the bibliography to check the kindness of the results. In all cases the surface of the embankment is horizontal $\beta=0^{\circ}$ and the wall has the back vertical $\alpha=90^{\circ}$. The thicknesses of the wall in the base and the on the top has been selected to the specific situations of every case.

The program verifies that the safety coefficients of sliding and overturning in seismic situation fulfill the following conditions:

$$
\text { FSD } \geq 1.10 \quad \text { FSV } \geq 1.50
$$

The following situations have been studied for these two types of walls:

- Wall with $4.00 \mathrm{~m}$ of height

1. Without earthquake, without cohesion and without friction soil-wall

2. Without earthquake, without cohesion and with friction soil-wall

3. Without earthquake, with cohesion and without friction soil-wall

4. Without earthquake, with cohesion and with friction soil-wall

- Wall with $6.00 \mathrm{~m}$ of height

5. Without earthquake, without cohesion and without friction soil-wall

6. With earthquake, without cohesion and without friction soil-wall

7. With earthquake, with cohesion and without friction soil-wall

8. With earthquake, with cohesion and with friction soil-wall

The summary of obtained results in are included in the following tables: 
Wall of $4.00 \mathrm{~m}$

\begin{tabular}{|c|c|c|c|c|c|c|c|}
\hline Wall & $\begin{array}{c}\mathbf{k}_{\mathbf{h}} \\
\left(\mathbf{k}_{\mathbf{v}}=\mathbf{1} \mathbf{2} \mathbf{k}_{\mathbf{h}}\right)\end{array}$ & $\begin{array}{c}\mathbf{c}_{\mathbf{1}}=\mathbf{c}_{\mathbf{2}} \\
(\mathbf{k P a})\end{array}$ & $\begin{array}{c}\mathbf{\delta} \\
\mathbf{( \mathbf { 0 }}\end{array}$ & $\begin{array}{c}\mathbf{B 1} \\
(\mathbf{m})\end{array}$ & $\begin{array}{c}\mathbf{B 2} \\
(\mathbf{m})\end{array}$ & $\mathbf{k}_{\text {crit }}$ & $\begin{array}{c}\mathbf{d}_{\mathbf{p e r m}} \\
(\mathbf{m m})\end{array}$ \\
\hline 1 & 0 & 0 & 0 & 1.80 & 1.30 & $0.120 \mathrm{~g}$ & 0 \\
\hline 2 & 0 & 0 & 15 & 1.60 & 1.20 & $0.161 \mathrm{~g}$ & 0 \\
\hline 3 & 0 & 10 & 0 & 1.50 & 1.20 & $0.083 \mathrm{~g}$ & 0 \\
\hline 4 & 0 & 10 & 15 & 1.30 & 1.10 & $0.126 \mathrm{~g}$ & 0 \\
\hline 5 & $0.10 \mathrm{~g}$ & 0 & 0 & 1.85 & 1.50 & $0.1497 \mathrm{~g}$ & 0.19 \\
\hline 6 & $0.10 \mathrm{~g}$ & 0 & 15 & 1.80 & 1.50 & $0.202 \mathrm{~g}$ & 0 \\
\hline 7 & $0.10 \mathrm{~g}$ & 10 & 0 & 1.60 & 1.30 & $0.1135 \mathrm{~g}$ & 1.84 \\
\hline 8 & $0.10 \mathrm{~g}$ & 10 & 15 & 1.50 & 1.00 & $0.1435 \mathrm{~g}$ & 0.28 \\
\hline
\end{tabular}

Table $\mathrm{n}^{\mathrm{o}} 1$ Exit of results for wall of height $\mathrm{H}=4.00 \mathrm{~m}$

Muro de $6.00 \mathrm{~m}$

\begin{tabular}{|c|c|c|c|c|c|c|c|}
\hline Wall & $\begin{array}{c}\mathbf{k}_{\mathbf{h}} \\
\left(\mathbf{k}_{\mathbf{v}}=\mathbf{1} / \mathbf{2} \mathbf{k}_{\mathbf{h}}\right)\end{array}$ & $\begin{array}{c}\mathbf{c}_{\mathbf{1}}=\mathbf{c}_{\mathbf{2}} \\
(\mathbf{k P a})\end{array}$ & $\begin{array}{c}\mathbf{\delta} \\
\left.\mathbf{(}^{\mathbf{0}}\right)\end{array}$ & $\begin{array}{c}\mathbf{B 1} \\
(\mathbf{m})\end{array}$ & $\begin{array}{c}\mathbf{B 2} \\
(\mathbf{m})\end{array}$ & $\mathbf{k}_{\text {crit }}$ & $\begin{array}{c}\mathbf{d}_{\text {perm }} \\
(\mathbf{m m})\end{array}$ \\
\hline 1 & 0 & 0 & 0 & 2.70 & 2,40 & $0.1439 \mathrm{~g}$ & 0 \\
\hline 2 & 0 & 0 & 15 & 2.30 & 2,10 & $0.1712 \mathrm{~g}$ & 0 \\
\hline 3 & 0 & 10 & 0 & 1.90 & 1,70 & $0.050 \mathrm{~g}$ & 0 \\
\hline 4 & 0 & 10 & 15 & 1.80 & 1,50 & $0.104 \mathrm{~g}$ & 0 \\
\hline 5 & $0.10 \mathrm{~g}$ & 0 & 0 & 2.80 & 2,50 & $0.163 \mathrm{~g}$ & 0 \\
\hline 6 & $0.10 \mathrm{~g}$ & 0 & 15 & 2.70 & 2,50 & $0.212 \mathrm{~g}$ & 0 \\
\hline 7 & $0.10 \mathrm{~g}$ & 10 & 0 & 2.20 & 1,90 & $0.0985 \mathrm{~g}$ & 4.72 \\
\hline 8 & $0.10 \mathrm{~g}$ & 10 & 15 & 2.10 & 1,90 & $0.1575 \mathrm{~g}$ & 0 \\
\hline
\end{tabular}

Table $\mathrm{n}^{\circ} 2$ Exit of results for wall of height $\mathrm{H}=6.00 \mathrm{~m}$

\section{CONCLUSIONS}

It has been analyzed 16 cases of walls of $4.00 \mathrm{~m}$ and $6.00 \mathrm{~m}$ of height for two values of the friction angle soil-wall and for two values of the cohesion of the landfill, one null and other different to zero.

The analysis of the permanent seismic displacement leads to the conclusion that walls that fulfill to stability in seismic situation can have unacceptable displacements, being advisable the determination of this value in the seismic design of a wall. This is the line followed nowadays for the "Performance Based Design" 


\section{REFERENCES}

[1] Brinkgreve, R. B. J. “Manual de Referencia de PLAXIS” Delf, 2004.

[2] Coulomb, C. A. "Essai sur une application des regles des maximis et minimis a quelques problemes de statique relatives a l'architecture” Memoires de l'Academie Royale pres Divers Savants, Vol. 7, 1776.

[3] Fajfar P, Krawinker H. "Seismic Design Methodologies for the next generation Codes" . Ed. Balkema. 1977

[4] International Building Code (IBC 2006).

[5] Lysmer, John, Ostadan, Farhang, Tabataie, Manour, Tajirian, Frederick and Vahdani, Shahriar, "SASSI 2000- A system for Analysis of Soil-Structure Interaction", 2000.

[6] Mononobe, N. and Matsuo H. On the Determination of Earth Pressures during Earthquakes” Proceedings $2^{\text {nd }}$ World Engineering Conference, Vol. 9, paper $n^{\circ} 388$, peg. 177-185, 1929.

[7] Newmark, N.M. "Effects of earthquakes on dams and embankments" Geotechnique, v. 15, n2, pag. 139-160, 1965.

[8] Prakash, S. and Wu, Y. "Displacement of rigid walls during earthquakes". Eleventh World Conference on Earthquake Engineering, 1996.

[9] Prakash, S. and Rafnsson, E. A. “On Seismic Design Displacements of Rigid Retaining Walls" Proceedings $3^{\text {rd }}$ International Conference on Recent Advances on Geotechnical Earthquake Engineering and Soil Dynamics, Vol.3, pag. 1183-1192, St. Luis, Missouri, 1995.

[10] Prakash, S. and Basvanna, B. M. "Earth Pressure Distribution Behind Retaining Walls During Earthquakes” Proceedings Fourth World Conference on Earthquake Engineering, Chile, Vol. 3, pag. 133-148, 1969.

[11] Priestley MJN “Performance Based Seismic Design” New Zealand National Society for Earthquake Engineering. 2000.

[12] Rankine, W. "On the Stability of loose Earth" Philosophical Transactions of the Royal Society of London, Vol. 147, 1857.

[13] Richards, R. and Elms, D. G. "Seismic Behavior of Gravity Retaining Walls" Journal of Geotechnical Engineering Division, ASCE, Vol. 105, No GT4, pag. 449-464, 1979.

[14] Scott, R. F. “Earthquake-Induced Earth Pressures on Retaining Walls” Proceedinds $5^{\text {th }}$ World Conference on Earthquake Engineering, Rome, Italy, pag. 1611-1620, 1973.

[15] Veletsos, A. S., Younan, A. H. and Bandyopadhyay "Dynamic Response of Cantilever Retaining Walls”. Department of Advanced Technology Brookhaven National Laboratory Associated Universities Inc. Upton, New York, October 1996.

[16] Whitman, R. V. and Samson Liao "Seismic Design of Gravity Retaining Walls". Report to U. S. Army Engineer Waterways Experiment Station, Vicksburg, Mississippi, 1983.

[17] Wood, John H.. “Earthquake Soil-Induced Soil Pressures on structures” Ph. D. Thesis, California Institute of Technology, EERL, 73-05, Pasadena, California, 1973. 